\title{
THEMATIC PROGRESSION ON THIRD GRADE STUDENTS' WRITING IN WWW.THEWRITESOURCE.COM
}

\author{
Lia Elyani Sukawatie \\ Sebelas Maret University, liaelyani@yahoo.com
}

\begin{abstract}
This paper aims at describing the thematic progression which appears in the native $3^{\text {rd }}$ grade students. This study examines the native students' writing, particularly their persuasive paragraph and narrative personal paragraph. The researcher took 2 texts out of 12 texts in www.thewritesource.com. The data analysis was grounded in the technique developed by Martin and Rother in Paltridge (2000:140). The result of this study showed that multiple theme patterns dominated the thematic progression development. The second one was reiteration theme, and the last was zig-zag pattern.
\end{abstract}

Keywords: Assessment, curriculum, portfolio, student assessment.

\section{INTRODUCTION}

In studying English, there are four skills which have to be mastering by the students. They are reading, listening, speaking and writing. One of them which are used to communicate is writing. According to Merriam Webster (2016), "writing is the act or process of one who writes: such as a : the act or art of forming visible letters or characters; specifically: handwriting." Writing also does not have any limitation in time and space. Writing is generally recognized as a difficult task for language learners, especially foreign language learners. They have difficulties in translating their native language to the target language, in producing ideas, and organizing them systematically. Maintaining the coherence in their writing is the main problem faced by the students when they are asked to write. As a matter of fact, it is not as essential as the students' errors found in the discourse level; that is, lack of coherence of writing. Coherence refers to contextual properties; 
that is the way in which relates to and makes sense in the situation in which it occurs. To achieve the coherent paragraph, each sentence relates clearly to the topic sentence or controlling idea, but there is more to coherence than this. As the result, the coherent paragraph will make each sentence flows smoothly into the next without overlapping or jumps. It also emphasizes the chains between old and new information to make the structure of ideas or arguments clear for the readers.

One of the ways that can be used to give correction or feedback to the students' writing is by analyzing the thematic progression in their writing. Thematic progression can be seen from the pattern of theme and rhyme used in their writing. Different patterns of thematic progression are used in different text types. This article is focused on the application of applying the patterns of thematic progression in U.S student writing $3^{\text {rd }}$ grade in www.thewritesource.com.

The Theme-Rheme concept is firstly introduced by Halliday (2014:37). He states that Theme is element which serves as the point of departure of the message; it is that with which the clause is concerned. The remainder of the message, the part in which Theme developed is called Rhem.

Actually, this concept is explained in Systemic Functional Linguistics (SFL). It analyzes language from its main functions. Butt, D. et al (2012:5-6) say that there are three main functions of language: (i) to talk about the experiences (experiential function) and to show the logical relationship between them (logical function); (ii) to interact and/or to express a point of view (interpersonal function); and (iii) to organize our experiential, logical, and interpersonal meanings into a coherent whole (textual function). Theme-Rheme is included in textual function. It is used to organize the meaning in whole context coherently.

This research tries to answer the question: What is the thematic progression which appears in native $3^{\text {rd }}$ grade students on www.thewritesource.com? Based on the Martin and Rother in Paltridge (2000:140) frame work, this paper was conducted to know Thematic Progression patterns in $3^{\text {rd }}$ grade writing in www.thewritesource.com. 


\section{LITERATURE REVIEW}

According to www.writesite.elearn.usyd.edu.au, thematic progression refers to the way Themes continually pick up information which is already in the text and repeat it in some way so that the reader is always aware of: what the key concepts are; and how the key concepts are being developed. By constantly 'recycling' information in the preceding sentences as Themes of the next, writers are able to create very strong links between one sentence and the next, and one paragraph and the next. It can be concluded that Theme can ties the clause coherently, so the text will be systematic. It is not enough for the writer to understand the links and connections. They must be fully visible to the readers. If they are not, the readers will experience high levels of frustration and are quite likely to simply stop reading. In English, there are several ways of using Theme to develop major threads in a text, but three ways of progressing from one sentence to the next are particularly common.

In linguistics, Theme position is as initial position in the clause, but Rheme is following initial position. Halliday, however, distinguished theme and rheme from given and new. The theme is what the writer or speaker chooses as the point of departure; the given is what the listener or reader already knows (or what is accessible for the listener or reader to know). Theme and rheme, then, is writer-oriented, while given and new is reader-oriented (Halliday 2014: 299). The term rheme eventually gave way to comment, and theme, following the usage of changed to topic. Based on Martin and Rother in Paltridge (2000:140), there are three kinds of thematic progression patterns, they are:

1. Theme reiteration/constant theme

The pattern of constant continuous theme shows up the theme of the first clause becomes the theme of the clauses that follow. This pattern can be seen in the figure below.

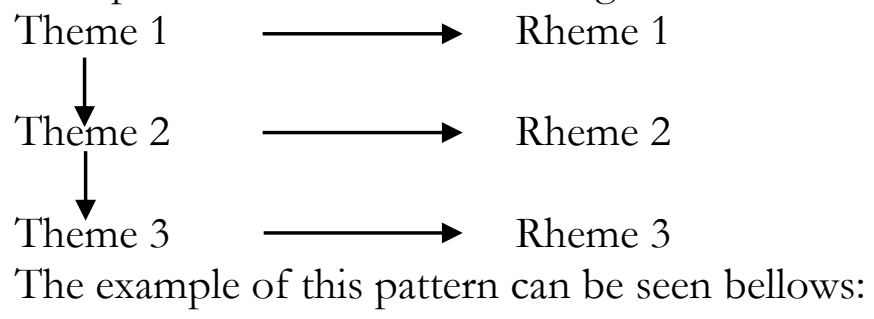


Oprah Winfrey was born in Mississippi on January 29, 1954. When she was 19 years old, she became the first AfricanAmerican news anchor on WTVF-TV in Nashville. She began The Oprah Winfrey Show, one of the most popular talk show in the United States. She got remarkable success in this program. She finally formed a company and (she) bought her own show.

2. Linear theme pattern

This patterns is also called zig-zag pattern (Eggins:1994), where the rheme of the first clause becomes the theme in the second sentence; the rheme of the second sentence becomes the theme of the third clause, and so forth. This pattern can be seen in the following figures.

Theme $2 \longrightarrow$ Rheme 1

The example of this pattern is:

Communication is a process of transmitting a message. The message can be delivered through oral or written expression. Through writing, people can communicate without limitation of distance and time.

3. Multiple theme/split rheme pattern

In this pattern, a rheme may include a number of different pieces of information, each of which may be taken up as the theme in a number of subsequent clauses. The example of multiple theme pattern can be seen below:

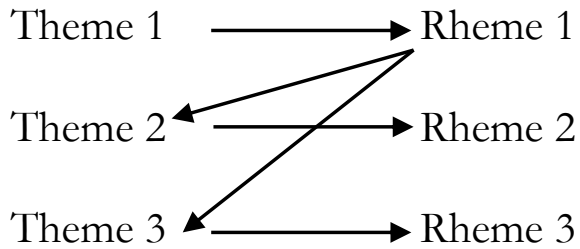

The example of this pattern is shown as follows:

Ecuador is situated on the equator in the northwest of South America. The economy is based on oil and agricultural products. More oil is produced in Ecuador than any other South American country except Venezuela. Bananas, coffee, and cocoa are grown there. The people are mostly of Indian 
origin. Several Indian languages are spoken there. The currency is called the Sucre.

\section{RESEARCH METHOD}

\section{Object of the Research}

In this paper, the object of the research is $3^{\text {rd }}$ grade writing. It is taken from www.thewritesource.com. The writing includes three kinds of genre: persuasive paragraph, classroom report and personal narrative. There are 23 clauses in the text. The first text is 11 clauses and the last text is 12 clauses. It is written by native students.

2. Unit of Analysis

Unit of analysis in this research is every clause in the text.

3. Technique of Data Collection

In this research, the writer is taken the data from www.thewritesource.com. The writer takes student writing of $3^{\text {rd }}$ grade students. The data is written form there are 4 genres includes 12 texts in the websites. Those are personal writing, subject writing, research writing and writing poem. The writer only took 2 texts from 12 texts.

4. Technique of Data Analysis

After the data were collected, it is analyzed by using Martin and Rother in Paltridge (2000:140) theory.

\section{FINDINGS AND DISCUSSION}

There are two genres of students' writing is used as the data of this research. The texts have differences in characteristic such as the topics, the length, the diction and etc. The topics which appear in the texts are: 1 . environment and 2. pets. The thematic progression of those texts will analyze based on Martin and Rother in Paltridge (200:140) as follows:

Text 1

Topic: Environment

\section{Plastic, Paper, or Cloth?}

We have a big decision to make. We can use cloth, paper, or plastic bags. I choose cloth because paper uses trees, and plastic 
uses petroleum; so we should use cloth. Cloth bags are easy to take with you and use again and again. We need to keep our earth clean, so let's use cloth. Remember, recycle and reuse.

The Themes and Rhemes of text 1 one is:

Table 1: Theme and Rheme Text 1

\begin{tabular}{|l|l|l|}
\hline $\begin{array}{l}\text { N } \\
\text { O. }\end{array}$ & \multicolumn{1}{|c|}{ THEME } & \multicolumn{1}{c|}{ RHEME } \\
\hline 1. & We & have a big decision to make. \\
\hline 2. & We & can use cloth, paper, or plastic bags. \\
\hline 3. & I & choose cloth \\
\hline 4. & Paper & uses trees \\
\hline 5. & Plastic & uses petroleum \\
\hline 6. & So we & should use clothes. \\
\hline 7. & Cloth bags & are easy to take with you \\
\hline 8. & Cloths bags & use again and again. \\
\hline 9. & We & need to keep our earth clean \\
\hline 10. & So let's & let's use cloth \\
\hline 11. & (We) & Remember, recycle and reuse. \\
\hline
\end{tabular}

From the text above, it can be seen that the student makes three kinds of thematic progression. First, he makes the reiteration. It can be seen from Theme 1, 2, 7, 8, 9, 10, and 11. The student makes repetition in theme 1 (we), it repeats in theme 2 . Theme 7 repeats in theme 8 (cloths bag). The last, Theme 9 (we) repeats in Theme 10 and Theme 11. Second, he makes zig-zag pattern. It can be seen in theme 7 (cloths bags) is the development of Rheme 6 . Third, he continues to make the text coherent by using multiple patterns. It is seen in Theme 3 (I), Theme 4 (paper), and Theme 5 (plastic) are the development from Rheme (2).

Based on Martin and Rother in Paltridge (2000:140) theory, the pattern of text 1 can be seen as follows:

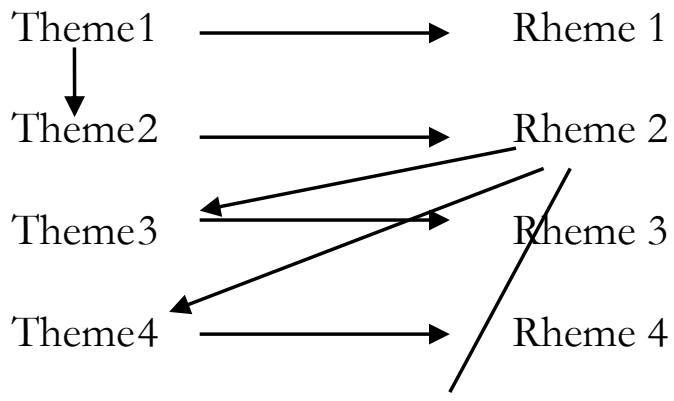




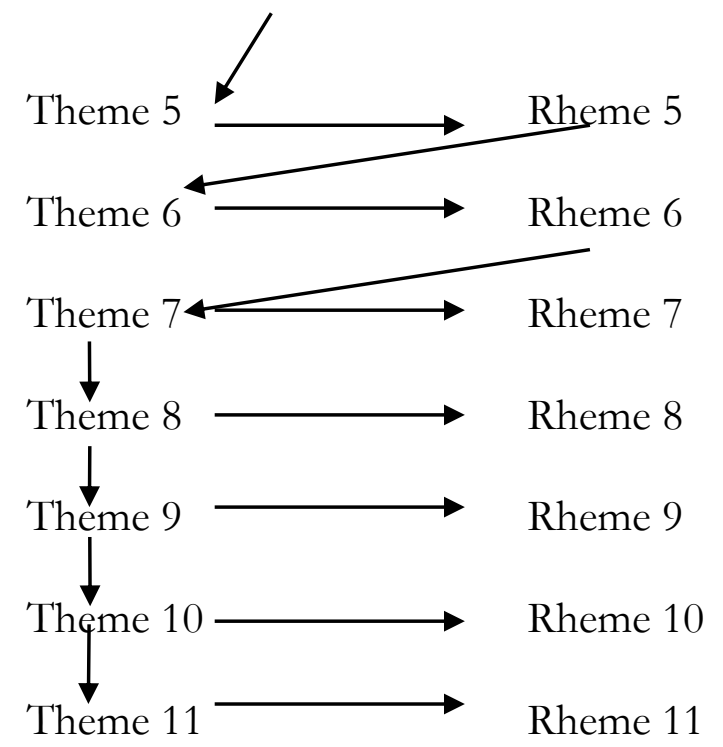

Text 2

Topic: Pets

\section{The Funny Dance}

I remember when my dog Murphy was really little. She was only two or three years old. It was on Christmas. My dad put on some Christmas music and Murphy put her paws up in the air and started swirling around in circles. Then she put her paws on my dad's hands and they started dancing together. It was very funny, and my dad thought that Murphy was a good dancer! The Themes and Rhemes of text 2 one is:

\section{Table 2: Theme and Rheme Text 2}

\begin{tabular}{|l|l|l|}
\hline NO. & THEME & RHEME \\
\hline 1. & I & remember \\
\hline 2. & When my dog Murphy & was really little. \\
\hline 3. & She & was only two or three years old. \\
\hline 4. & It & was on Christmas. \\
\hline 5. & My dad & put on some Christmas music \\
\hline 6. & Murphy & put her paws up in the air \\
\hline 7. & (Murphy) & $\begin{array}{l}\text { started swirling around in } \\
\text { circles. } \\
\text { put her paws on my dad's } \\
\text { hands }\end{array}$ \\
\hline 8. & Then she & \\
\hline
\end{tabular}


Sukawatie, L. E., Thematic Progression ...

\begin{tabular}{|l|l|l|}
\hline 9. & and they & started dancing together. \\
\hline 10. & It & was very funny. \\
\hline 11. & And my dad & thought \\
\hline 12. & That Murphy & was a good dancer! \\
\hline
\end{tabular}
thematic progression. Those are: thematic reiteration, zig-zag, and multiple theme patterns. Theme reiteration can be seen in Theme 7 (Murphy) and Theme 8 (Murphy) is repetition of Theme 6 (she). Zigzag theme applies in Theme 9 (and they) is developed from Rheme 8 (put her paws on my dad's hands). Theme 10 (it) is developed from Rheme 9 (put her paws on my dad's hands). The last thematic progression is multiple theme patterns. It can be seen in Theme 1 (I) developes to Rheme 1 (remember). Theme 2 (when my dog), Theme 3 (she), Theme 4 (it), Theme 5 (my dad) and Theme 6 (Murpy) is developed from Rheme 1 (remember). Theme 11 (and my dad) and Theme 12 (that Murphy) are developed from Rheme 10 (was very funny).

Based on Martin and Rother in Paltridge (2000:140) theory, the pattern of text 1 can be seen as follows:

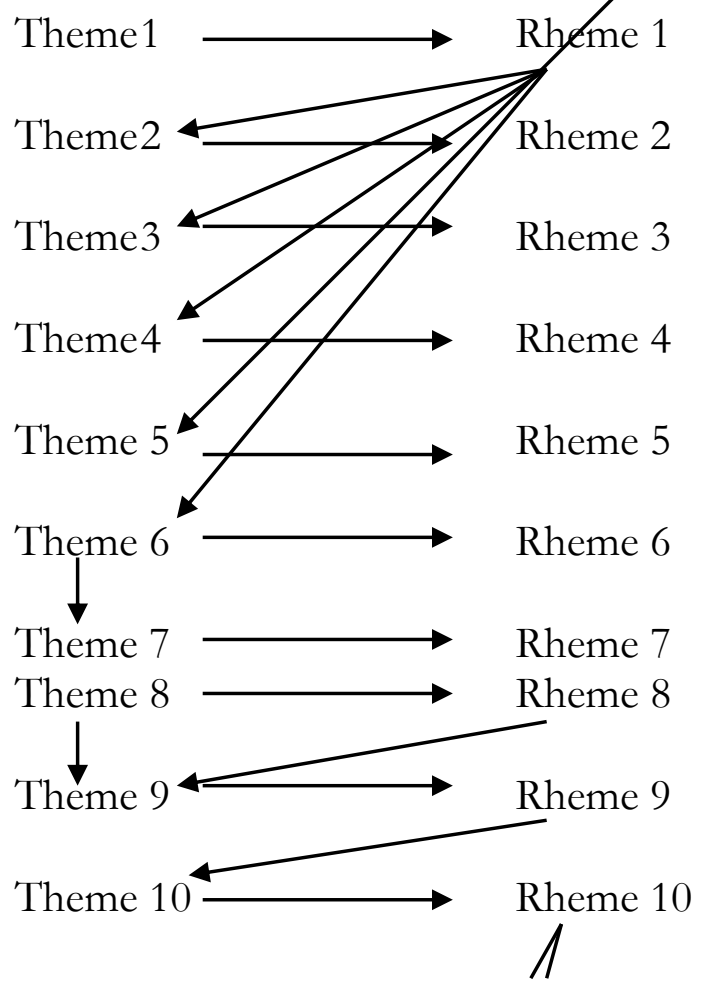




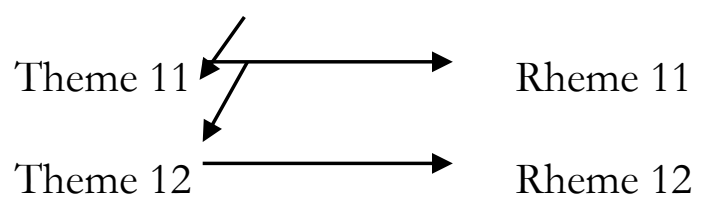

From the short explanation above, it can be concluded as the table follows:

\begin{tabular}{ccccc}
\hline $\begin{array}{c}\text { No of } \\
\text { Text }\end{array}$ & $\begin{array}{c}\text { Reiteration } \\
\text { Theme }\end{array}$ & Zig-zag & $\begin{array}{c}\text { Multiple } \\
\text { theme } \\
\text { patterns }\end{array}$ & Total \\
\hline 1 & 7 & 1 & 3 & 11 \\
\hline 2 & 2 & 2 & 8 & 12 \\
\hline Total & 9 & 3 & 11 & 23 \\
\hline In text 1 , reiteration theme dominates the text with 7
\end{tabular}

themes. On the other hand, in text 2, multiple theme patterns dominate with 8 themes. Totally, multiple theme patterns dominate in both texts with 11 themes. The second rank is reiteration theme with 9 themes. And the last rank is zig-zag.

\section{CONCLUSION}

From the previous discussion, it can be concluded that thematic progression that applies in the both texts is dominated with Multiple Theme Patterns. The second rank is Reiteration Theme and the last one is Zig-zag. The Multiple Theme Patterns become the dominant one because the students develop previous Rheme. On the other hand, Reiteration Theme become the second preferred because the students just repeat the previous Theme. Zig-zag pattern becomes the least because it is more difficult than multiple theme patterns and reiteration. In this writing, thematic progression does not break because those text write by native speaker.

\section{REFERENCES}

Butt, D., Fahey, R., Spinks, S., \& Yallop, C. (2012). Using functional grammar: An explorer's guide. Sydney: National Centre for English Language Teaching and Research: Macquarie University. 
Sukawatie, L. E., Thematic Progression ...

Halliday, M. A. K. (1968). Notes on transitivity and theme in English (part3). Journal of Linguistics, 4(2), 179-215.

Halliday, M. A. K. (2014). An introduction to functional grammar (4th Ed.). London: Edward Arnold.

Hockett, Charles. 1959. A Course in Modern Linguistics. New York: Macmillan.

Sansalone, Neil S et al. (2016). Merriam webster dictionary. USA: Merriam Webster Incorporated. Retrieved from http://writesite.elearn.usyd.edu.au/m3/m3u5/m3u5s3/m3 u5s3_6.htm

www.thewritesource.com. (2017, July 20). Retrieved from http://www.thewritesource.com/ 